Document downloaded from:

http://hdl.handle.net/10251/101462

This paper must be cited as:

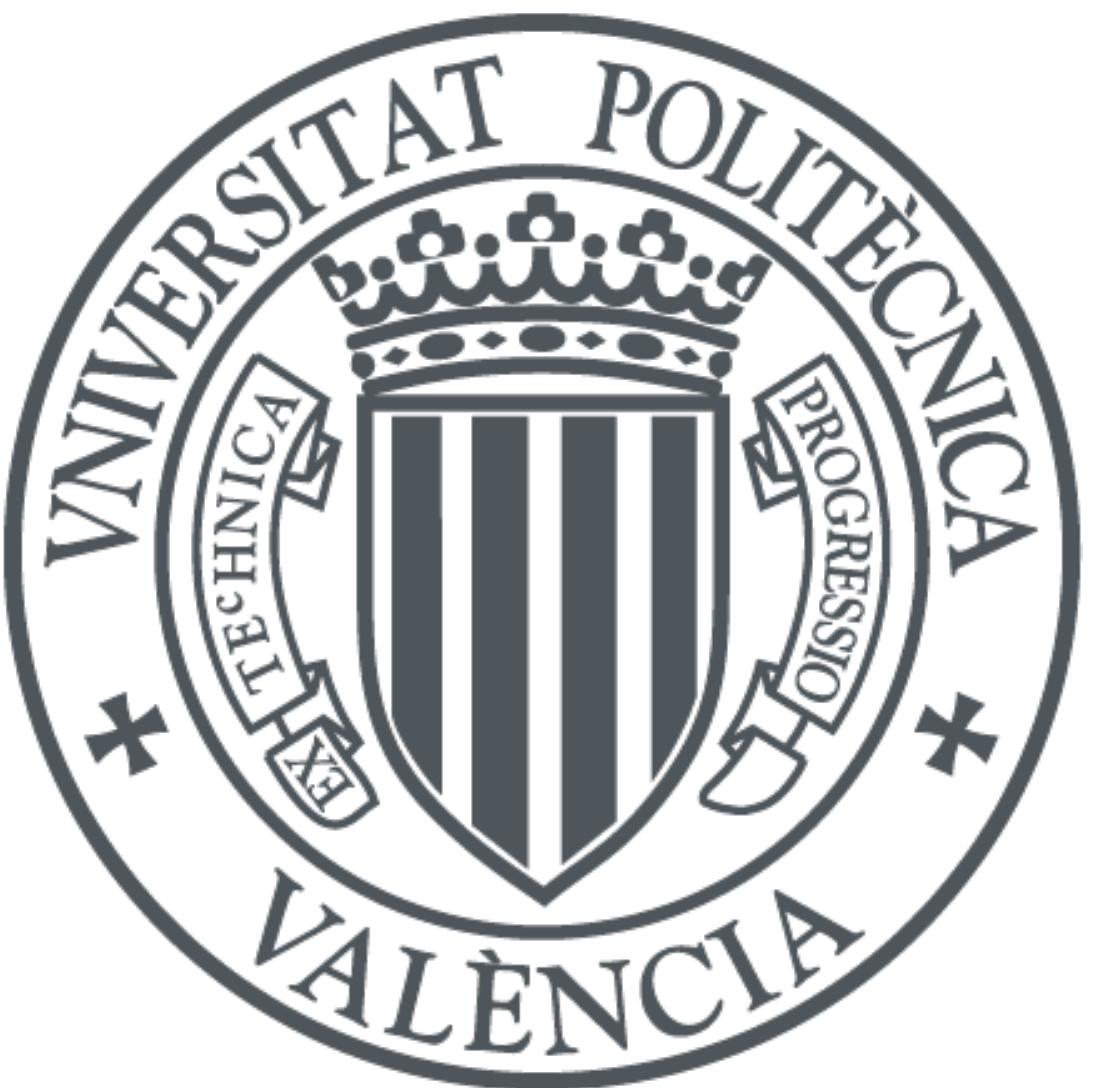

The final publication is available at

http://doi.org/10.1016/j.molcata.2013.11.015

Copyright Elsevier

Additional Information 


\title{
Conversion of levulinic acid derived valeric acid into a liquid transportation fuel of the kerosene type
}

\author{
Avelino Corma ${ }^{\mathrm{a}, *}$, Borja Oliver-Tomas ${ }^{\mathrm{a}}$, Michael Renz ${ }^{\mathrm{a}, *}$, Irina L. Simakova ${ }^{\mathrm{b}}$ \\ a Instituto de Tecnología Química, Universitat Politècnica de Valencia-Consejo \\ Superior de Investigaciones Científicas (UPV - CSIC), Av. de los Naranjos s/n, E-46022 \\ Valencia, Spain \\ b Boreskov Institute of Catalysis, Lavrentieva 5, 630090 Novosibirsk, Russian \\ Federation
}

\begin{abstract}
In the transformation of lignocellulosic biomass into fuels and chemicals carbon-carbon bond formations and rising hydrophobicity are highly desired. The ketonic decarboxylation fits these requirements perfectly as it converts carboxylic acids into ketones forming one carbon-carbon bond and eliminates three oxygen atoms as carbon dioxide and water. This reaction is used, in a cascade process, together with a hydrogenation and dehydration catalyst to obtain hydrocarbons in the kerosene range from hexose-derived valeric acid. It is shown that zirconium oxide is a very selective and stable catalyst for this process and when combined with platinum supported on alumina, the oxygen content was reduced to almost zero. Furthermore, it is demonstrated that alumina is superior to active carbon, silica or zirconium oxide as support for the hydrogenation/dehydration/hydrogenation sequence and a palladiumbased catalyst deactivated more rapidly than the platinum catalyst. Hence, under optimized reaction conditions valeric acid is converted into $n$-nonane with $80 \%$ selectivity (together with a $10 \%$ of $\mathrm{C}_{10}$ to $\mathrm{C}_{15}$ hydrocarbons) in the organic liquid phase up to a $100: 1$ feed to catalyst ratio [wt/wt]. The oxygen free hydrocarbon product mixture (85\% yield) meets well the boiling point range of kerosene as evidenced by a simulated distillation. In the gas phase butane was detected together with mainly carbon dioxide.
\end{abstract}

\footnotetext{
* Corresponding Authors.

E-mail address: acorma@itq.upv.es; mrenz@itq.upv.es
} 


\section{Keywords}

catalyst stability; ketonic decarboxylation; ketone hydrodeoxygenation; Pt/alumina; zirconium oxide 


\section{Introduction}

Carboxylic acids play a predominant role in biomass transformations into fuels and chemicals when lignocellulose is considered as raw material. On one hand they form part of the bio-oils obtained by pyrolysis of lignocellulosic biomass. In these complex mixtures, volatile carboxylic acids such as acetic, formic acid, and higher homologues (acrylic acid, butyric acid, isobutyric acid, valeric acid, isovaleric acid, etc.) can be found in lower concentration [1,2,3,4]. On the other hand, carboxylic acids such as levulinic acid are available in a more selective way with yields of 55\% (with respect to the hexose content) from ground hardwood [5] or up to $70 \%$ from other raw materials [6] via hydrolysis of hexoses like in the Biofine process [5]. In aqueous acid conditions hexoses are first dehydrated to 5-hydroxymethylfurfural (HMF) and this compound is then rehydrated and cleaved into levulinic acid and formic acid (eq. 1) [7]. Therefore, levulinic acid is generally considered as a biomass-based building block and manifold conversions into chemicals and fuels have been proposed.

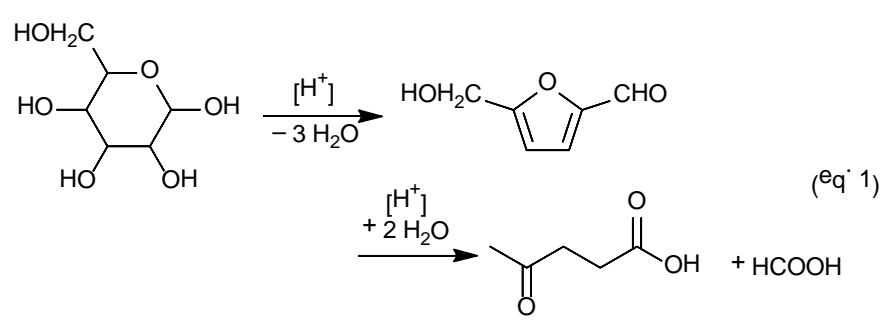

For both, fuels and chemicals, the reduction of the oxygen content is an important issue. Hereby, the reduction of levulinic acid into valeric (pentanoic) acid is straightforward via $\gamma$-valerolactone (GVL) $[8,9]$. In a certain version of the reaction exploiting the raw material to a maximum, formic acid co-produced in the re-hydration of HMF has been used as hydride donor in the first step $[10,11]$. For further reducing the oxygen content when treating carboxylic acids, and increasing the molecular weight at the same time which is also highly desired in biomass transformations, the ketonic decarboxylation is a very suitable and environmentally benign reaction [12]. This reaction is carried out at elevated temperatures $\left(350-400{ }^{\circ} \mathrm{C}\right.$ ) in the presence of a catalyst and two molecules of carboxylic acid are fused to a ketone, expelling one molecule of carbon dioxide and one of water (eq. 2). Further reagents are not required. Hence, from this sequence, i.e. dehydration, rehydration, hydrogenation, and ketonic decarboxylation, compounds such as 5-nonanone are available from hexoses (eq. 3).

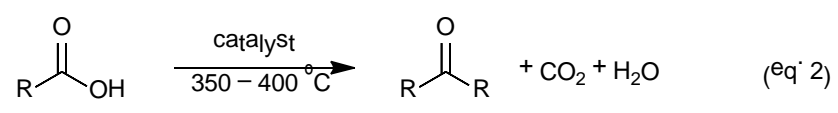




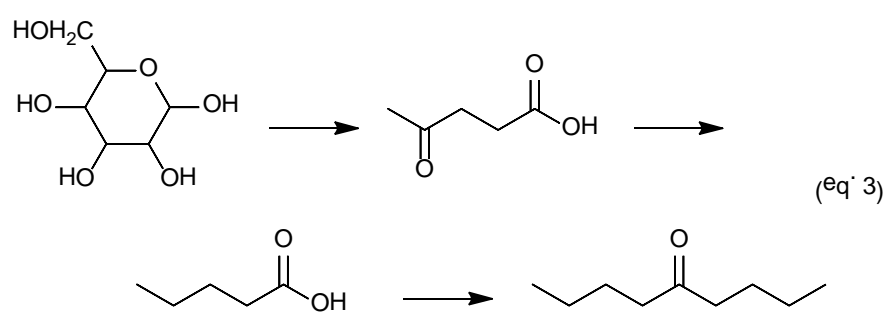

Probably the ketonic decarboxylation also plays a decisive role in the stabilization of the above mentioned bio-oils. When using them as a co-feed in fluid catalytic cracking units (FCCs) they need a significant up-grade due to their high oxygen content [13]. Catalysts (e.g. alkali and alkaline earth metal oxides supported on amorphous silica alumina) and reaction conditions $\left(450{ }^{\circ} \mathrm{C}\right)$ [14] resemble those of the ketonic decarboxylation for which a catalytic action of these oxides has been established in other cases $[15,16]$. Furthermore, increased decarboxylation and dehydration has been observed for the pyrolysis in presence of these catalysts together with the reduction of the carboxylic acid amount.

Hence, these examples show the increasing interest in the ketonic decarboxylation for the production of ketones since first performed more than a century ago [12]. Then, the reaction mechanism [17] has been studied in detail by means of theoretical DFT calculations $[18,19]$. Thereby, it has been found that a reaction mechanism via a $\beta$-keto acid requiring hydrogen atoms in $\alpha$-position is kinetically favored (Scheme 1 ). In a first step two molecules of carboxylic acid are adsorbed onto the surface and "stabilized" for the reaction in a different way. One molecule is deprotonated twice to yield an enediolate and the other molecule is dehydroxylated. Then, the methylene group attacks nucleophlically the carbonyl group of the dehydroxylated acid forming a $\beta$-keto acid. The latter is decarboxylated to an enolate. Protonation and desorption of all reaction products allow to close the catalytic cycle.

This theoretical study has been carried out with zirconium dioxide as catalyst which has been shown to be the most active material among zirconium-cerium mixed oxide, cerium oxide, alumina or silica [18]. The catalytic advantages of zirconium oxide have been confirmed in a further study [20]. Therefore, this is a material to be tested in multistep transformations such as presented for the conversion of fatty acids into diesel and lubricants [21]. In a cascade reaction the fatty acids have been converted into fatty ketones over magnesium oxide, the ketones hydrogenated to alcohols and hydrocarbons have been obtained by subsequent dehydration and olefin hydrogenation (Scheme 2). The maximum selectivity towards the corresponding hydrocarbon, i.e. tricosane from 
lauric acid, was 58\%. However, except for one case and using approximately the same amount of feed as the weight of catalyst, deoxygenation was lower than $80 \%$ since, generally, the corresponding ketone was observed with more than $20 \%$ selectivity. The activity of the ketonic decarboxylation catalyst decreased with time on stream.

In the present manuscript we show the possibility of obtaining good yields of kerosene from levulinic acid in a two-bed one fixed-bed continuous reactor by combining $\mathrm{ZrO}_{2}$ and $\mathrm{Pt} / \mathrm{Al}_{2} \mathrm{O}_{3}$ in the presence of hydrogen. The catalyst is stable under reaction conditions.

\section{Experimental part}

Valeric acid (98\%) and decanoic acid (99\%) were purchased from Sigma Aldrich and 5nonanone from Acros. All reagents were used without any further purification. $\mathrm{ZrO}_{2}$, $\mathrm{Al}_{2} \mathrm{O}_{3}$ and $\mathrm{SiO}_{2}$ were received from ChemPur and activated carbon from Norit. $\mathrm{H}_{2} \mathrm{PtCl}_{6}$ - $6 \mathrm{H}_{2} \mathrm{O}$ (99\%, Aldrich) and $\mathrm{Pd}(\mathrm{OAc})_{2}$ (Aldrich, 99\%) were employed as noble metal precursors.

The metal catalysts were prepared by the incipient wetness impregnation method. Solutions with the corresponding concentrations of $\mathrm{H}_{2} \mathrm{PtCl}_{6} \cdot 6 \mathrm{H}_{2} \mathrm{O}$ and of $\mathrm{Pd}(\mathrm{OAc})_{2}$ were prepared in water and toluene, respectively. The metal oxide supports were impregnated as pellets $(0.4-0.8 \mathrm{~mm})$ and dried in vacuum. In the case of $\operatorname{Pd}(\mathrm{OAc})_{2}$ several impregnation steps were required to achieve the desired metal load. At the end of the impregnation procedure all catalysts were dried in an oven overnight at $100{ }^{\circ} \mathrm{C}$.

Reactions were carried out in a reactor described elsewhere [18] with a back-pressure regulator placed at the exit of the reactor for pressure control. When decanoic acid was employed as substrate all parts of the reactor that were in contact with the substrate were heated to $45{ }^{\circ} \mathrm{C}$ (melting point of decanoic acid $32{ }^{\circ} \mathrm{C}$ ). In general the feed was passed with a rate of $0.15 \mathrm{~mL} / \mathrm{min}$, and reaction temperature of the catalytic bed was $400{ }^{\circ} \mathrm{C}$. At the exit of the reactor the product was condensed $\left(0^{\circ} \mathrm{C}\right)$ and analyzed offline by gas chromatography. In the ketonic decarboxylation with $\mathrm{ZrO}_{2}$ the mass balance for the liquid phase was $97 \% \pm 2 \%$ (Calculated with respect to the theoretical yield, resting the weight of carbon dioxide and water). With $\mathrm{Pt} / \mathrm{Al}_{2} \mathrm{O}_{3}, \mathrm{Pt} / \mathrm{SiO}_{2}$ and $\mathrm{Pt} / \mathrm{C}$ as a second catalytic bed the weight balance was $85 \%$ (Calculated again with respect to the theoretical yield having in mind the hydrogen introduced and resting the weight of carbon dioxide and two molecules of water). With $\mathrm{Pd} / \mathrm{Al}_{2} \mathrm{O}_{3}$ and with $\mathrm{Pt} / \mathrm{ZrO}_{2}$ the weight balance was $80 \%$ and $65 \%$, respectively. With $\mathrm{Pt} / \mathrm{ZrO}_{2}$ as single bed the mass 
balance was 55 to $70 \%$. Gaseous effluents were analyzed off-line on a GC apparatus equipped with three detectors. Two detectors were thermal conductivity detectors (TCD) for the analysis of $\mathrm{H}_{2}$ (separated on a $2 \mathrm{~m}$ molecular sieve $5 \AA$ column) and of $\mathrm{CO}, \mathrm{CO}_{2}$, and $\mathrm{N}_{2}$ (separated on a $2.5 \mathrm{~m}$ molecular sieve $13 \mathrm{X}$ column). The third detector was a flame ionization detector (FID) for the analysis of $\mathrm{C}_{1}$ to $\mathrm{C}_{5}$ hydrocarbons separated on a $50 \mathrm{~m} \mathrm{Plot} / \mathrm{Al}_{2} \mathrm{O}_{3}$ column. Main components were $\mathrm{CO}_{2}, \mathrm{CO}$, methane, butane and pentane depending on the catalyst of the second catalytic bed.

The amount of water obtained for the ketonic decarboxylation is stated in the caption of Figure 2. Yield might be lowered by incomplete condensation. The amount of water obtained in the hydrodeoxygenation of 5-nonanone at $400{ }^{\circ} \mathrm{C}$ is stated in caption of Figure 4. Again, yield might be lowered by incomplete condensation. The yields of water phases for the combined ketonic decarboxylation and hydrodeoxygenation are stated in the captions of Figures 5, 6, and 8 to 11. The stoichiometrical amount would be two equivalents. A higher amount might be due to carbon dioxide methanation and a lower stoichiometric amount due to incomplete condensation as stated before.

The metal-containing catalysts were activated (reduced) in-situ in the reactor. The reactor was purged with nitrogen and then with hydrogen. Applying a hydrogen pressure of 40 bar and a hydrogen flow of $470 \mathrm{~mL} / \mathrm{min}$ the catalyst was treated at the boiling point of the solvent used for the impregnation step during one hour and at 400 ${ }^{\circ} \mathrm{C}$ for two hours. The heating ramp was $9 \% \mathrm{~min}$ in all cases.

The ketonic decarboxylation of decanoic acid was carried out at a contact time (W/F) of $0.31 \mathrm{~h}$ employing $2.5 \mathrm{~g}$ of zirconium oxide. When the reaction was carried out with valeric acid with a contact time (W/F) of $0.074 \mathrm{~h} 1.0 \mathrm{~g}$ of zirconium oxide was used. The study of the bifunctional catalyst for ketonic decarboxylation and hydrogenation in one bed, i.e. with $3 \% \mathrm{Pt} / \mathrm{ZrO}_{2}$, was carried out with $2.5 \mathrm{~g}$ of catalyst. In the two-catalytic bed process $2.5 \mathrm{~g}$ of zirconium oxide was employed for the ketonic decarboxylation in the first bed and $1.5 \mathrm{~g}$ of the hydrogenation catalyst placed downstream.

The conversion has been calculated by the following formula:

Conversion $/ \%=100-$ (Selectivity of the substrate in the organic liquid phase $\mathrm{x}$ Mass balance for the organic liquid/\%)/100

The yield for the different organic compounds can be calculated by the following formula: 
Yield $/ \%=$ (Selectivity in the organic phase $/ \% \mathrm{x}$ Conversion $/ \% \mathrm{x}$ Mass balance for the organic liquid/\%)/10 000

\section{Results and Discussion}

The stability of zirconium oxide with time on stream was first tested under the standard reaction conditions employed for the selection of this metal oxide as active material for the ketonic decarboxylation [18]. Hence, decanoic acid was passed as feed with a contact time, defined as weight of catalyst per weight of feed passed during one hour (W/F), of $0.31 \mathrm{~h}$. Under these conditions the conversion was complete and the selectivity towards the corresponding ketone, i.e. 10 -nonadecanone, was $>95 \%$ in the organic liquid (Figure 1). This result does not change during 24 h time on stream, when already $100 \mathrm{~g}$ of substrate was passed per g of catalyst and the mass balance for organic and aqueous liquid phase was $97 \%$. To better study catalyst deactivation, the contact time was decreased $(\mathrm{W} / \mathrm{F}=0.074 \mathrm{~h})$, so the conversion was lower than $100 \%$. The substrate feed was changed to the hexose biomass-derived valeric acid. The latter was selected as biomass-derived starting material for the present study. With these changes the initial conversion was $85 \%$ and it decreased approximately 15 percentage points to $70 \%$ when passing more than $90 \mathrm{~g}$ of substrate per gram of catalyst (Figure 2). At this point the reaction was stopped, the catalyst reactivated by calcination $\left(500{ }^{\circ} \mathrm{C}, 2 \mathrm{~h}\right.$, air flow of $50 \mathrm{~mL} / \mathrm{min}$ ) and, after this treatment, the initial activity and conversion was practically recovered (Figure 2). Hence, the catalytic cycle was carried out four times with three intermediate activation steps. After the whole reaction/reactivation sequence the values for the conversion were approximately 5\% lower than the initial ones indicating that the catalyst can be subjected to cycles of reaction-regeneration. At this point, we concluded that zirconium oxide was not only an active and selective catalyst for the ketonic decarboxylation as reported before [18] but also stable with time on stream. Therefore, the oxide was considered as a suitable catalyst for the first step in a combined process including ketonic decarboxylation and hydrogenation. Furthermore, the change of the carrier gas from nitrogen to hydrogen should not have a negative effect on the catalytic performance as demonstrated before [20].

After the fourth in-situ calcination of the catalyst, a thermogravimetric analysis showed that no organic deposits remained on the surface. In fact, up to a temperature of $200{ }^{\circ} \mathrm{C}$ only $2 \%$ weight loss was observed that was attributed to water desorption. In the 
temperature range from 200 to $800{ }^{\circ} \mathrm{C}$ the weight reduction was an additional one percent which might also be due to dehydration reactions. The BET surface area of the used catalyst was significantly decreased from $104 \mathrm{~m}^{2} / \mathrm{g}$, measured with the fresh catalyst, to $78 \mathrm{~m}^{2} / \mathrm{g}$ after the catalytic reaction.

Since the catalytic behavior of $\mathrm{ZrO}_{2}$ for the ketonic decarboxylation was quite good, we decided to prepare a bifunctional metal/ $\mathrm{ZrO}_{2}$ catalyst to perform in a single catalytic bed the ketonic decarboxylation and the hydrogenation-dehydration-hdyrogenation of the ketone formed. It has been shown that stearic acid [22] or tall oil derived fatty acids [23] are decarboxylated in the presence of supported platinum or palladium catalysts with excellent conversion and high yield of the corresponding $n-1$ hydrocarbons [24]. Interestingly, the reaction temperature was also elevated, namely between 300 and 350 ${ }^{\circ} \mathrm{C}$. An acidic tungsten/zirconium mixed oxide [25] has also been used as catalyst support, but selectivity towards the corresponding n-1 hydrocarbon did not exceed $60 \%$. In our work, $3 \mathrm{wt} \%$ of Pt was supported onto zirconium oxide, placed into a tubular stainless-steel reactor and reduced in situ at $400{ }^{\circ} \mathrm{C}$ during $2 \mathrm{~h}$ at 40 bar hydrogen pressure. For a preliminary study, decanoic acid was preferred over valeric acid, since the corresponding product, i.e. nonane was easier to condense and to analyze off-line than butane. From Figure 3 it can be seen that, indeed, nonane was the main product in the liquid organic phase with selectivities ranging from 55\% to $80 \%$ over the whole range of tested hydrogen pressures (1 to 20 bar). The low mass balance in the liquid phase (55-70\%) indicates that further fragmentation reactions occur giving hydrocarbons in the gas phase. Products with nineteen carbon atoms such as nonadecanone or nonadecane were observed in significant amount ( $>5 \%)$ only at a one bar hydrogen pressure.

The extensive fragmentation observed with the bifunctional catalyst prompted us to separate the two processes, i.e. ketonic decarboxylation and hydrodeoxygenation by using two consecutive catalytic beds. The top bed was formed by $\mathrm{ZrO}_{2}$ which nicely catalyzes the ketonic decarboxylation, while the second bed was formed by $\mathrm{Pt} / \mathrm{Al}_{2} \mathrm{O}_{3}$ as catalyst that should perform well the hydrogenation reaction. However, in a previous step, the hydrogenation of a ketone (5-nonanone) was studied on $\mathrm{Pt} / \mathrm{Al}_{2} \mathrm{O}_{3}$ under different reaction temperatures $\left(100-400{ }^{\circ} \mathrm{C}\right)$ and pressures (1-40 bar). The results

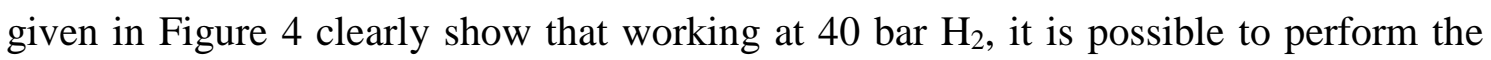
hydrogenation of the ketone with high activity and selectivity at $400{ }^{\circ} \mathrm{C}$ that matches the temperature required for the ketonic decarboxylation. Then, a process can be used that 
involves one fixed bed reactor with two consecutive catalytic beds: $\mathrm{ZrO}_{2}$ and $\mathrm{Pt} / \mathrm{Al}_{2} \mathrm{O}_{3}$, by working at $400{ }^{\circ} \mathrm{C}$ and 40 bar of hydrogen.

At this point, valeric acid was passed through a continuous flow reactor at $400{ }^{\circ} \mathrm{C}$ with two catalytic beds, i.e. zirconium oxide ( $2.5 \mathrm{~g}$ ) and platinum supported on alumina (1.5 g) while the flow of valeric acid was $9.0 \mathrm{~g} \mathrm{~h}^{-1}$. When the contact time was shortened to the half, i.e. doubling the feed rate from $9.0 \mathrm{~g} \mathrm{~h}^{-1}$ to $18.0 \mathrm{~g} \mathrm{~h}^{-1}$, the selectivity towards the desired nonane was constant at an $80 \%$ level of the liquid organic phase (yield of the organic phase $85 \%$, Figure 5) but the conversion of the intermediary 5-nonanone decreased slightly and $10 \%$ of the ketone remained in the effluent of the continuous flow reactor.

Valeric acid was passed up to a ratio of 100 g per gram of zirconium oxide and $85 \%$ was recovered as liquid product. From Figure 6 it can be seen that the yield of nonane in the liquid organic phase did not change with time on stream and no indication of catalyst deactivation was detected. This is a considerable improvement with respect to the previous system $\mathrm{MgO}-\mathrm{Pt} / \mathrm{Al}_{2} \mathrm{O}_{3}$ employed for the synthesis of lubricants [21]. Probably, the better stability of the first catalytic bed with time on stream, avoiding the contact of the hydrodeoxygenation bed with unreacted carboxylic acids, was also the reason for the improved stability of the second catalytic bed.

Interestingly, a 10\% fraction of hydrocarbon products within a range of ten to fifteen carbon atoms was detected in the liquid organic phase. This revealed that besides the ketonic decarboxylation, further carbon-carbon bond formation occurred under the present reaction conditions. The main product (60\%) was 4-methylnonane as identified by GC-MS. We assume that it was formed on the ketone stage with partly reduced carbon dioxide to methanol (methylation) or formaldehyde (aldol condensation with subsequent hydrogenation). The simulated distillation demonstrated that the boiling point range of the whole product mixture matched well with the one of kerosene fuel from $145^{\circ} \mathrm{C}$ to $300{ }^{\circ} \mathrm{C}$ (Figure 7).

In summary, it was concluded that the combination of zirconium oxide as ketonic decarboxylation catalyst together with platinum supported onto alumina for the hydrogenation/dehydration/hydrogenation sequence was a very suitable system with respect to deoxygenation and maintaining this catalytic performance.

We have also considered other Pt supported catalysts. Hence, as alternative supports silica, active carbon and zirconium oxide were used and palladium was also used as an alternative hydrogenation functionality. With silica as support the hydrogenation of 5- 
nonanone was not complete and $20 \%$ of this compound was detected in the reactor effluent at a similar mass balance of $85 \%$ for the liquid phase (Figure 8). Furthermore, the hydrogenation activity decreased immediately after having passed an amount of feed equal to twice the weight of the catalyst. In contrast, with zirconium oxide as support the deoxygenation was almost complete (Figure 9). However, the selectivity towards the desired nonane hydrocarbon started at $65 \%$ and decreased rapidly to below $50 \%$. The reason for the low selectivity was the formation of shorter chain hydrocarbons formed by cracking of nonane or one of its precursors, as we saw before. This fragmentation was also reflected in the amount of organic liquid recovered that decreased from $85 \%$ to $65 \%$. In the gas phase ethane, propane and butane were detected in significant amounts, and when they were considered, the mass balance was $100 \% \pm 2 \%$. With active carbon as support for the platinum similar results as for alumina were observed. Nonane was obtained with almost $80 \%$ selectivity of the liquid organic phase (mass balance $85 \%$ as for $\mathrm{Pt} / \mathrm{Al}_{2} \mathrm{O}_{3}$ ), but a small part of 5-nonanone up to $5 \%$ was still present in the product stream (Figure 10).

It is assumed that the support helps to dehydrate the intermediary alcohol formed by ketone hydrogenation (cf. Scheme 2) and for this activity a well-balanced Brönstedacidity is required. In this respect it seems that the sites of alumina have the best properties, closely followed by the active carbon. In the case of silica the strength of the sites is too low evidenced by a low and easily deactivated deoxygenation activity. In contrast, zirconium oxide possesses too strong sites inducing, apart from the desired complete dehydration, additional undesired fragmentation reactions. These fragmentation reactions lower also the mass balance for the liquid phase from $85 \%$ for the other catalysts to $65 \%$ when using $\mathrm{Pt} / \mathrm{ZrO}_{2}$ as hydrodeoxygenation catalyst.

When the platinum (on alumina) was substituted by palladium the results were very similar or even improved. The selectivity towards nonane was slightly improved to $85 \%$ (versus $80 \%$ ) and also a small quantity of $\mathrm{C}_{10}$ to $\mathrm{C}_{15}$ hydrocarbons was observed at a slightly lower mass balance for the liquid phase, i.e. 80\% instead of 85\% (Figure 11). However, after passing a 30-fold amount of the weight of the catalyst, the selectivity for nonane started to decrease and finally reached half of the initial value. As reported before, with platinum on alumina 100 times the catalyst weight of feed was passed without any change in the catalytic performance. The reason for the lower selectivity in the case of palladium was the deactivation of the hydrogenation activity evidenced by the increasing selectivity for 5-nonanone (Figure 11). 
Therefore, it can be concluded that alumina, in combination with platinum, was the most efficient material for the selective transformation of the intermediary 5-nonanone into nonane. Palladium losses rapidly the hydrogenation activity and other supports were either less selective (zirconium oxide) or less active (active carbon, silica).

\section{Conclusion}

The combination of zirconium oxide with platinum supported onto alumina, placed in this order in a fixed bed continuous flow reactor, is a very suitable catalytic system to convert carboxylic acids into a hydrocarbon mixture. At a reaction temperature of 400 ${ }^{\circ} \mathrm{C}$ the ketonic decarboxylation on zirconium oxide presented high selectivity and excellent stability with time on stream. It can be reactivated by calcination so that after several cycles only a 5\% decrease in activity was observed. The hydrogenation/dehydration/hydrogenation catalyst platinum/alumina provided complete elimination of the oxygen with an excellent stability with time on stream. Hence, approximately $250 \mathrm{~g}$ of valeric acid were converted into a hydrocarbon mixture with 2.5 $\mathrm{g}$ of zirconium oxide and $1.5 \mathrm{~g}$ of platinum/alumina without observing any catalyst deactivation. It was shown that alternative supports such as silica, zirconium oxide or active carbon or palladium instead of platinum achieved incomplete deoxygenation or showed a rapid decrease in the catalytic activity.

The boiling point range of the product mixture matched well with the one of kerosene although for an application as jet fuel further isomerization might be advantageous. When hexose-derived valeric acid was employed as substrate, approximately $80 \%$ of the product was $n$-nonane plus another $10 \%$ of $\mathrm{C}_{10}$ to $\mathrm{C}_{15}$ hydrocarbons are present in the liquid organic phase (85\% mass balance). Butane was detected in the gas phase together with carbon monoxide, carbon dioxide and methane, and the global mass balance was closed with $100 \% \pm 2 \%$.

\section{Acknowledgement}

The authors thank MINECO (Consolider Ingenio 2010-MULTICAT, CSD2009-00050 and CTQ2011-27550) and the Spanish National Research Council (CSIC, Es 2010RU0108). B. O.-T. is grateful to CSIC for a fellowship (JAE Programme).

\section{References}

[1] A. Demirbas, Fuel Process. Technol. 88 (2007) 591-597. 
[2] K. Sipilä, E. Kuoppala, L. Fagernäs, A. Oasmaa, Biomass Bioenerg. 14 (1998) 103113.

[3] C.B. Rasrendra, B. Girisuta, H.H. van de Bovenkamp, J.G.M. Winkelman, E.J. Leijenhorst, R.H. Venderbosch, M. Windt, D. Meier, H.J. Heeres, Chem. Eng. J. 176177 (2011) 244-252.

[4] Z. Qi, C. Jie, W. Tiejun, X. Ying, Energ. Convers. Manage. 48 (2007) 87-92.

[5] S.W. Fitzpatrick, US Patent 4897497 (1988).

[6] S. Ritter, Chem. Eng. News 84 (2006) 47.

[7] G. Yang, E.A. Pidko, E.J.M. Hensen, J. Catal. 295 (2012) 122-132.

[8] J.P. Lange, R. Price, P.M. Ayoubm, J. Louis, L. Petrus, L. Clarke, H. Gosselink, Angew. Chem. Int. Ed. 49 (2010) 4479-4483.

[9] J.C. Serrano-Ruiz, D. Wang, J.A. Dumesic, Green. Chem. 12 (2010) 574-577.

[10] H. Heeres, R. Handana, D. Chunai, C.B. Rasrendra, B. Girisuta, H.J. Heeres, Green Chem. 11 (2009) 1247-1255.

[11] L. Deng, J. Li, D.-M. Lai, Y. Fu, Q.-X. Guo, Angew. Chem. Int. Ed. 48 (2009) $6529-6532$.

[12] M. Renz, Eur. J. Org. Chem. (2005) 979-988.

[13] T.S. Nguyen, M. Zabeti, L. Lefferts, G. Brem, K. Seshan, Biomass Bioenerg. 48 (2013) 100-110.

[14] M. Zabeti, T.S. Nguyen, L. Lefferts, H.J. Heeres, K. Seshan, Bioresource Technol. 118 (2012) 374-381.

[15] M. Renz, A. Corma, Eur. J. Org. Chem. (2004) 2036-2039.

[16] J.A. Sullivan, N. Walsh, L. Sherry, Catal. Lett. 143 (2013) 361-369.

[17] R.W. Snell, B.H. Shanks, Appl. Catal. A: Gen. 451 (2013) 86-93.

[18] A. Pulido, B. Oliver-Tomas, M. Renz, M. Boronat, A. Corma, ChemSusChem 6 (2013) 141-151.

[19] A.V. Ignatchenko, J. Phys. Chem. C 115 (2011) 16012-16018.

[20] Y.A. Zaytseva, V.N. Panchenko, M.N. Simonov, A.A. Shutilov, G.A. Zenkovets, M. Renz, I.L. Simakova, V.N. Parmon, Topics Catal. 56 (2013) 846-855.

[21] A. Corma, M. Renz, C. Schaverien, ChemSusChem 1 (2008) 739-741.

[22] M. Snare, I. Kubickova, P. Mäki-Arvela, K. Eränen, D.Y. Murzin, Ind. Eng. Chem. Res. 45 (2006) 5708-5715.

[23] P. Mäki-Arvela, B. Rozmyslowicz, S. Lastari, O. Simakova, K. Eränen, T. Salmi, D.Y. Murzin, Energ. Fuels 25 (2011) 2815-2825. 
[24] E. Santillan-Jimenez, M. Crocker, J. Chem. Technol. Biotechnol. 87 (2012) 10411050 .

[25] A.S. Berenblyum, V.Y. Danyushevsky, E.A. Katsman, T.A. Podoplelova, V.R. Flid, Petrol. Chem. 50 (2010) 305-311. 
Scheme 1. Kinetically favored mechanism on zirconium oxide as established by theoretical DFT calculations (see Ref. [18]). Two molecules of carboxylic acid are adsorbed in a different way onto the zirconium oxide surface, one by double deprotonation and the second by dehydroxylation. Then a carbon-carbon bond is formed between both molecules resulting in a $\beta$-keto acid. The latter is decarboxylated easily and protonation and desorption provides the ketone.

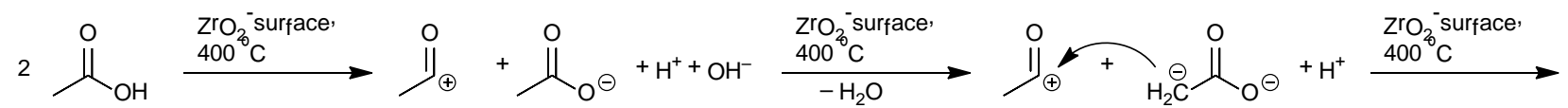

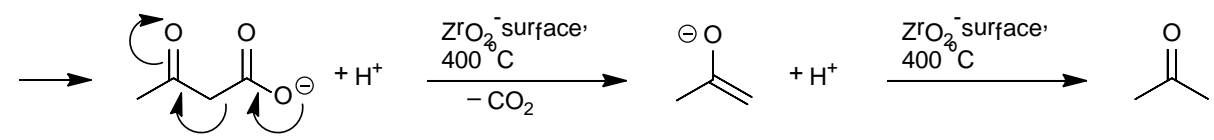

Scheme 2. Reaction sequence involving ketonic decarboxylation, hydrogenation of the resulting ketone to an alcohol, dehydration of this compound and hydrogenation of the intermediary olefin. For $\mathrm{R}=n$-octyl see Ref. [21]; $\mathrm{R}=\mathrm{Me}$, this work.

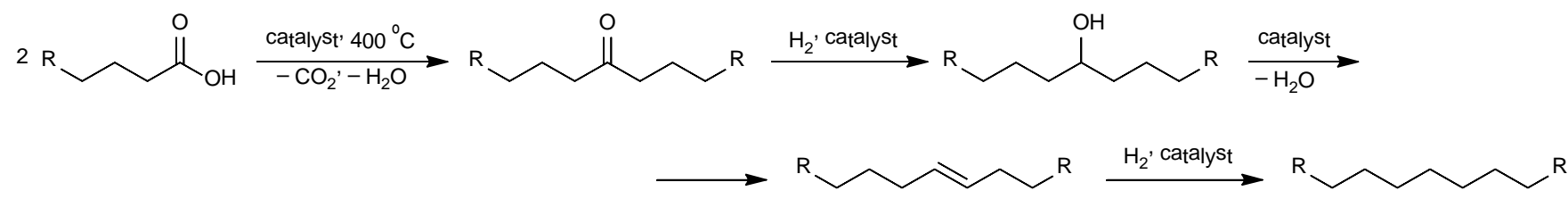


Figure 1. Conversion and selectivity in the organic liquid phase for the ketonic decarboxylation of decanoic acid over a fixed bed of zirconium oxide placed into continuous reactor. conversion pentanoic acid, $\Delta$ selectivity 10 -nonadecanone; for calculation of the yield see corresponding formula in the experimental part.

Reaction conditions: feed rate for decanoic acid: $0.31 \mathrm{~mL} / \mathrm{min}$; nitrogen gas flow: 50 $\mathrm{mL} / \mathrm{min} ; 400^{\circ} \mathrm{C}$ reaction temperature.

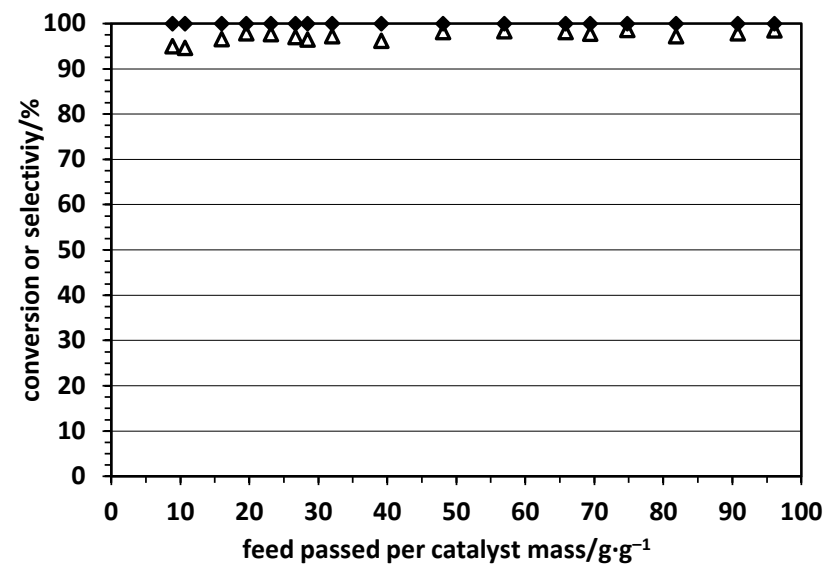


Figure 2. Conversion and selectivity in the organic liquid phase for the ketonic decarboxylation of valeric acid over a fixed bed of zirconium oxide placed into continuous reactor at shorter contact time and with reactivation steps. • conversion pentanoic acid $1^{\text {st }}$ cycle, + selectivity 5 -nonanone $1^{\text {st }}$ cycle, o conversion pentanoic acid $2^{\text {nd }}$ cycle, - selectivity 5-nonanone $2^{\text {nd }}$ cycle, - conversion pentanoic acid $3^{\text {rd }}$ cycle, $\times$ selectivity 5 -nonanone $3^{\text {rd }}$ cycle, $\Delta$ conversion pentanoic acid $4^{\text {th }}$ cycle, $*$ selectivity 5 nonanone $4^{\text {th }}$ cycle.

Reaction conditions: $1.00 \mathrm{~g}$ of catalyst was employed instead of $2.5 \mathrm{~g}$; feed rate for valeric acid: $0.24 \mathrm{~mL} / \mathrm{min}$; nitrogen gas flow: $50 \mathrm{~mL} / \mathrm{min} ; 400{ }^{\circ} \mathrm{C}$ reaction temperature. After each cycle the catalyst was calcined in-situ. The yield of the water phase was $47 \%$ on average.

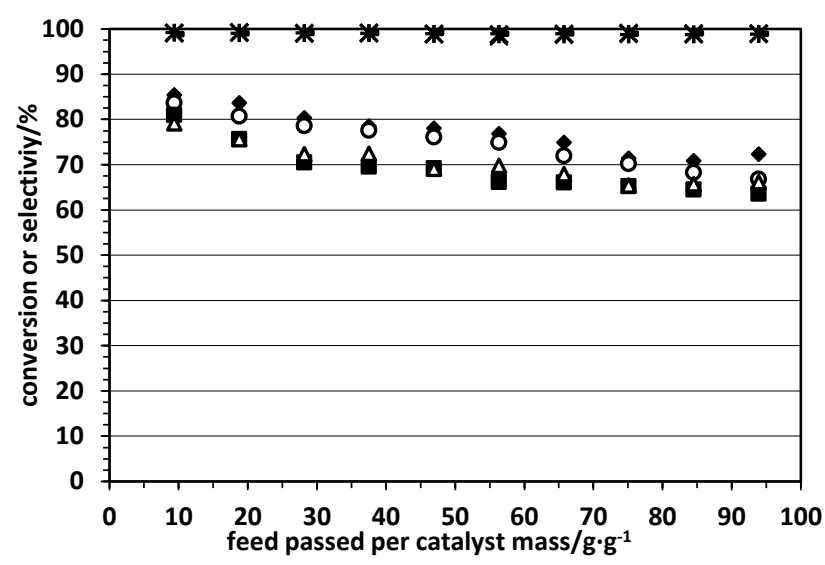


Figure 3. Conversion and selectivity in the organic liquid phase for the ketonic decarboxylation of decanoic acid over a fixed bed of platinum supported onto zirconium oxide placed into continuous reactor at different hydrogen pressures. conversion decanoic acid, o selectivity nonane, $\square$ selectivity to 10 -nonadecanone, $\Delta$ selectivity nonadecane, + selectivity to other hydrocarbons, * selectivity to decane.

Reaction conditions: feed rate for decanoic acid: $0.15 \mathrm{~mL} / \mathrm{min}$; hydrogen gas flow: 430 $\mathrm{mL} / \mathrm{min} ; 400^{\circ} \mathrm{C}$ reaction temperature.

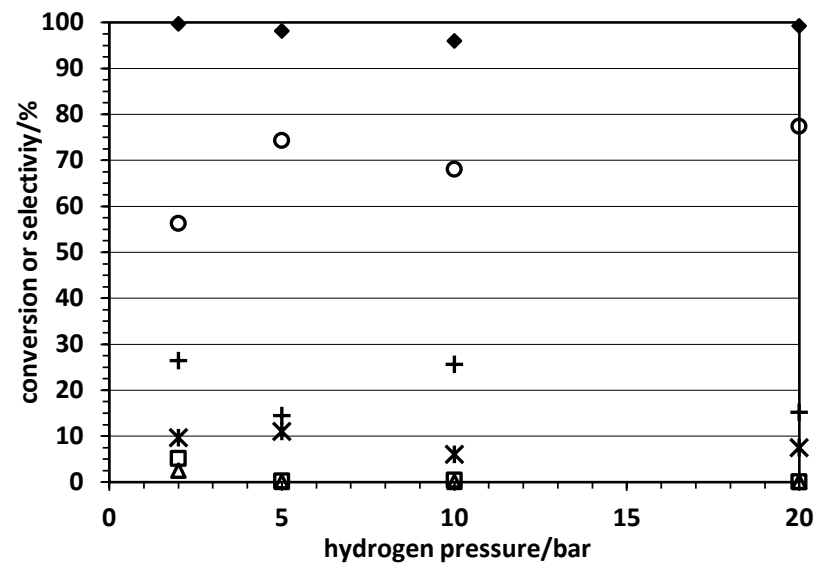


Figure 4. Conversion of 5-nonanone over a Pt/alumina catalytic bed at different temperatures: a) 100 ${ }^{\circ} \mathrm{C}$, b) $200{ }^{\circ} \mathrm{C}$, c) $300{ }^{\circ} \mathrm{C}$, and d) $400{ }^{\circ} \mathrm{C}$. 5-nonanone can be hydrogenated to 5-nonanol, the alcohol dehydrated and the resulting olefin again hydrogenated to yield $n$-nonane. conversion 5 -nonanone, $\square$ selectivity nonane, $\circ$ selectivity to 5-nonanol, $\Delta$ selectivity 4-nonene, + selectivity to other hydrocarbons, $*$ selectivity to oxygenated compounds.

Reaction conditions: $1.5 \mathrm{~g}$ of catalyst was employed; feed rate for 5-nonanone: $0.15 \mathrm{~mL} / \mathrm{min}$; hydrogen gas flow $470 \mathrm{~mL} / \mathrm{min}$. At $400{ }^{\circ} \mathrm{C}$ the yield of the water phase was $37 \%$ on average.

a)

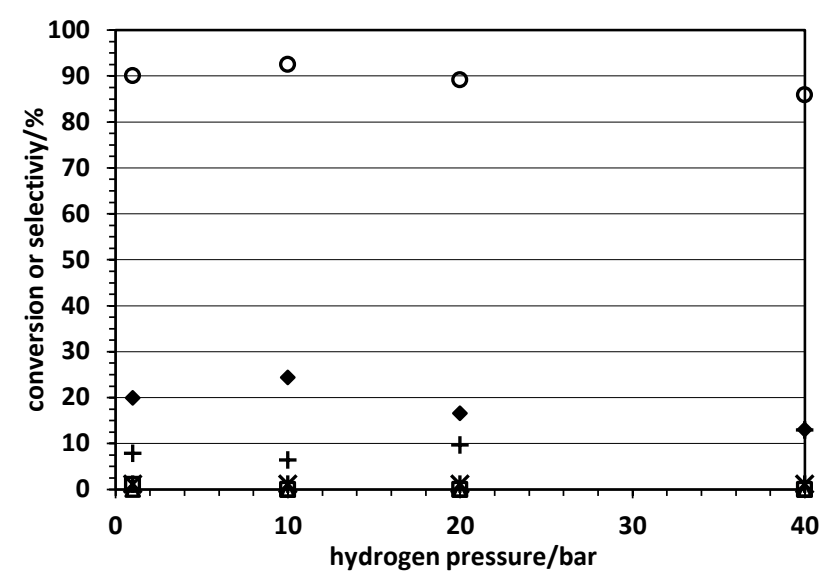

C)

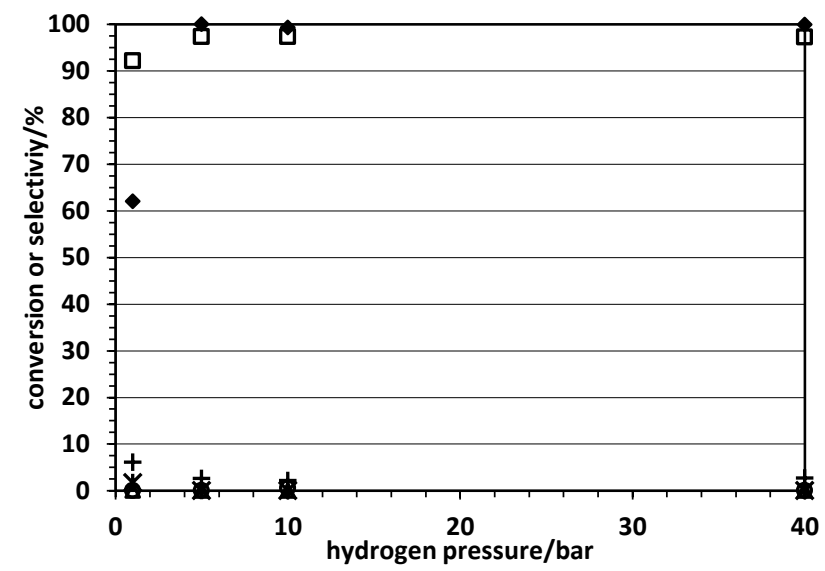

b)

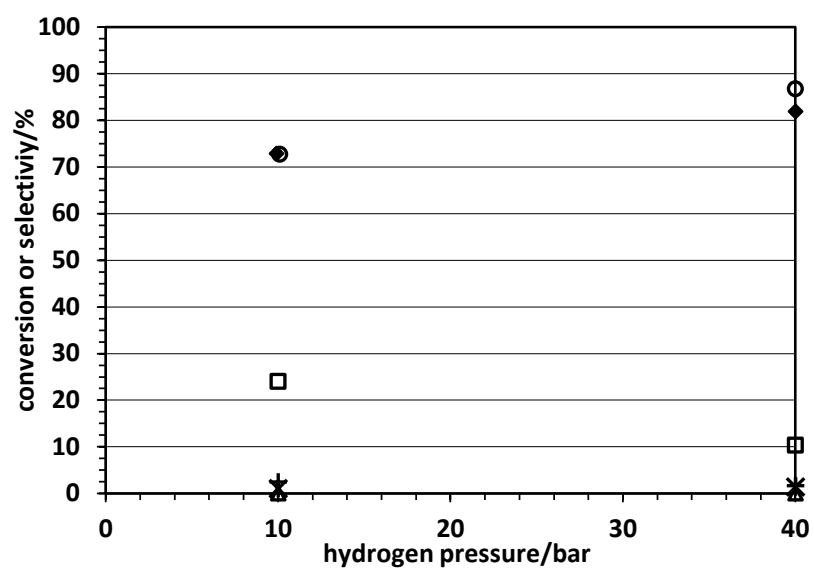

d)

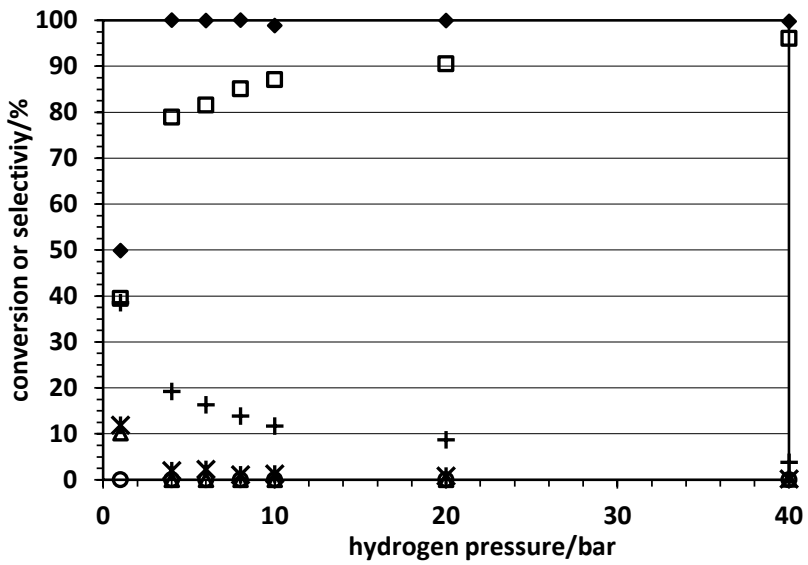


Figure 5. Conversion and selectivities in the organic liquid phase for the transformation of valeric acid over a zirconium oxide and a Pt/alumina bed at different contact times W/F. conversion pentanoic acid, $\Delta$ selectivity 5-nonanone, $\square$ selectivity nonane, $\circ$ selectivity to $\mathrm{C}_{10}-\mathrm{C}_{15}$ hydrocarbons, + selectivity to other hydrocarbons (up to $\mathrm{C}_{8}$ ), * selectivity to oxygenated compounds.

Reaction conditions: hydrogen gas flow: $470 \mathrm{~mL} / \mathrm{min}$; 40 bar hydrogen pressure; $400{ }^{\circ} \mathrm{C}$ reaction temperature. The yield of the water phase was 2.1 equiv. per valeric acid employed on average.

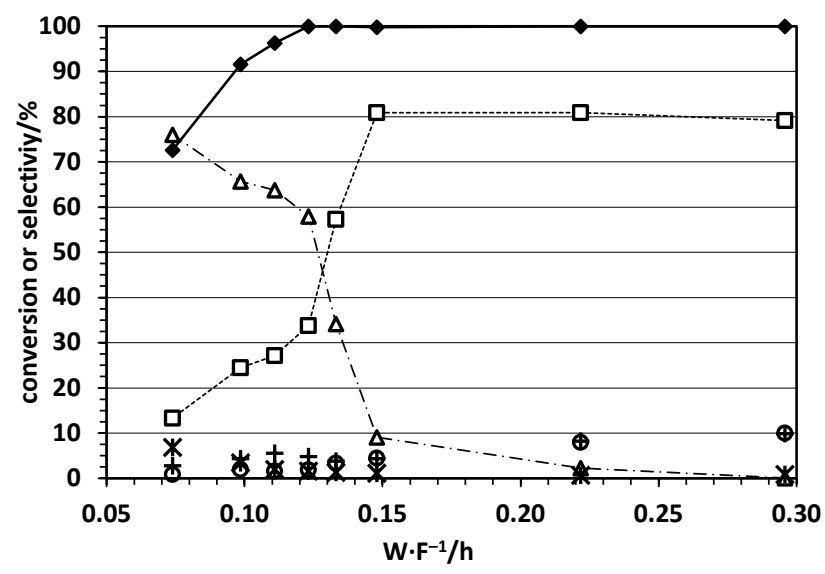


Figure 6. Development of conversion and selectivity in the organic liquid phase with time on stream when valeric acid was passed over a zirconium oxide and a Pt/alumina bed. conversion pentanoic acid, $\Delta$ selectivity 5-nonanone, $\square$ selectivity nonane, $\circ$ selectivity to $\mathrm{C}_{10}-\mathrm{C}_{15}$ hydrocarbons, + selectivity to other hydrocarbons (up to $\mathrm{C}_{8}$ ), * selectivity to oxygenated compounds; for calculation of the yield see corresponding formula in the experimental part.

Reaction conditions: feed rate for valeric acid: $0.15 \mathrm{~mL} / \mathrm{min}$; hydrogen gas flow: 470 $\mathrm{mL} / \mathrm{min}$; 40 bar hydrogen pressure; $400{ }^{\circ} \mathrm{C}$ reaction temperature. The yield of the water phase was 2.6 equiv. per valeric acid employed on average.

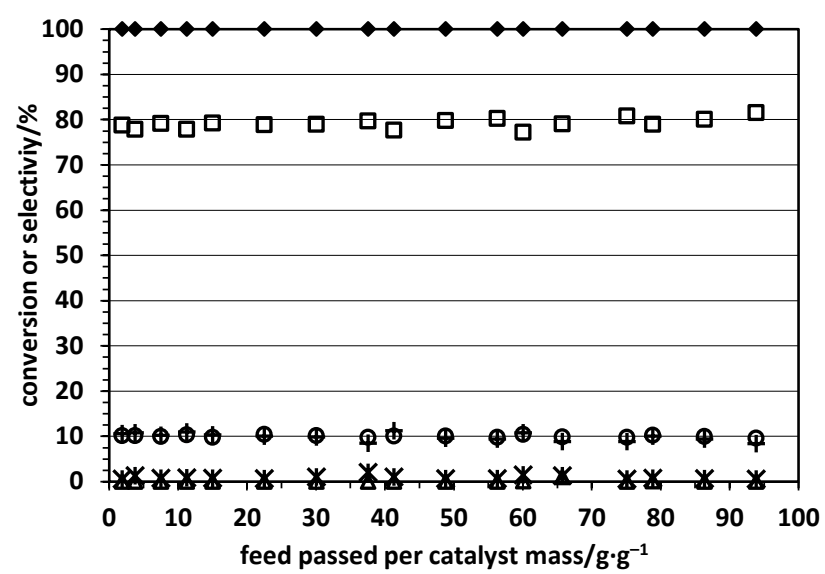


Figure 7. Simulated distillation for the product mixture obtained when valeric acid was passed over a zirconium oxide and a Pt/alumina bed (cf. Figure 6) at a basis of a kerosene boiling point range from $145^{\circ} \mathrm{C}$ to $300{ }^{\circ} \mathrm{C}$.

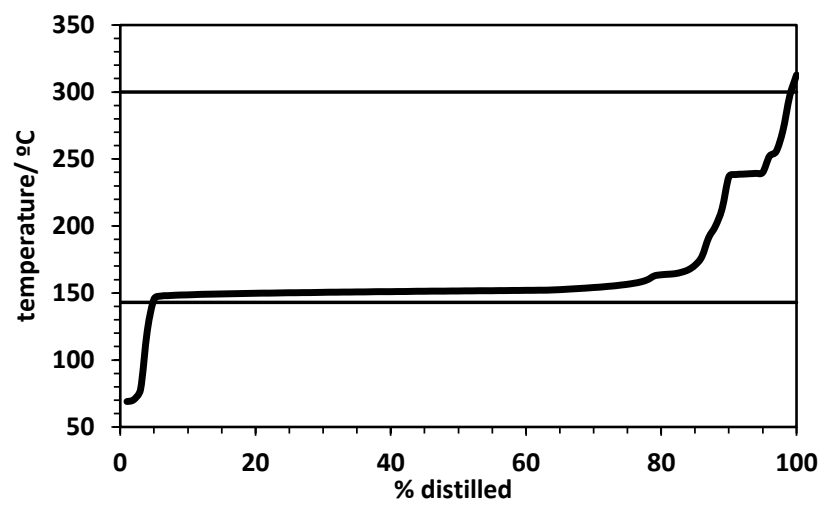


Figure 8. Development of conversion and selectivity in the organic liquid phase with time on stream when valeric acid was passed over a zirconium oxide and a Pt/silica bed. - conversion pentanoic acid, $\Delta$ selectivity 5-nonanone, $\square$ selectivity nonane, 0 selectivity 4-nonene, + selectivity to other hydrocarbons (up to $\mathrm{C}_{8}$ ), $*$ selectivity 5nonanol.

Reaction conditions: feed rate for valeric acid: $0.15 \mathrm{~mL} / \mathrm{min}$; hydrogen gas flow: 470 $\mathrm{mL} / \mathrm{min}$; 40 bar hydrogen pressure; $400{ }^{\circ} \mathrm{C}$ reaction temperature. The yield of the water phase was 0.75 equiv. per valeric acid employed on average.

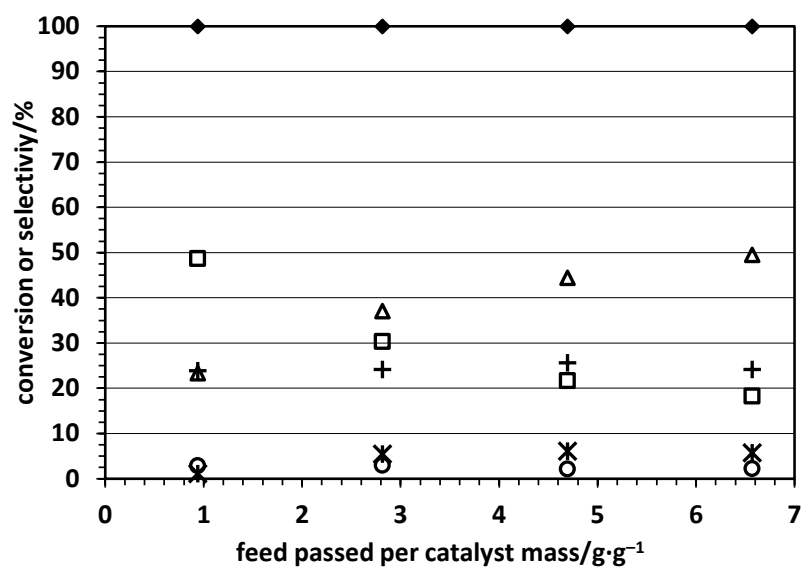


Figure 9. Development of conversion and selectivity in the organic liquid phase with time on stream when valeric acid was passed over a zirconium oxide and a Pt/zirconium oxide bed. $\bullet$ conversion pentanoic acid, $\Delta$ selectivity 5 -nonanone, $\square$ selectivity nonane, o selectivity to $\mathrm{C}_{10}-\mathrm{C}_{15}$ hydrocarbons, + selectivity to other hydrocarbons (up to $\mathrm{C}_{8}$ ), * selectivity to oxygenated compounds.

Reaction conditions: feed rate for valeric acid: $0.15 \mathrm{~mL} / \mathrm{min}$; hydrogen gas flow: 470 $\mathrm{mL} / \mathrm{min} ; 40$ bar hydrogen pressure; $400{ }^{\circ} \mathrm{C}$ reaction temperature. The yield of the water phase was 1.2 equiv. per valeric acid employed on average.

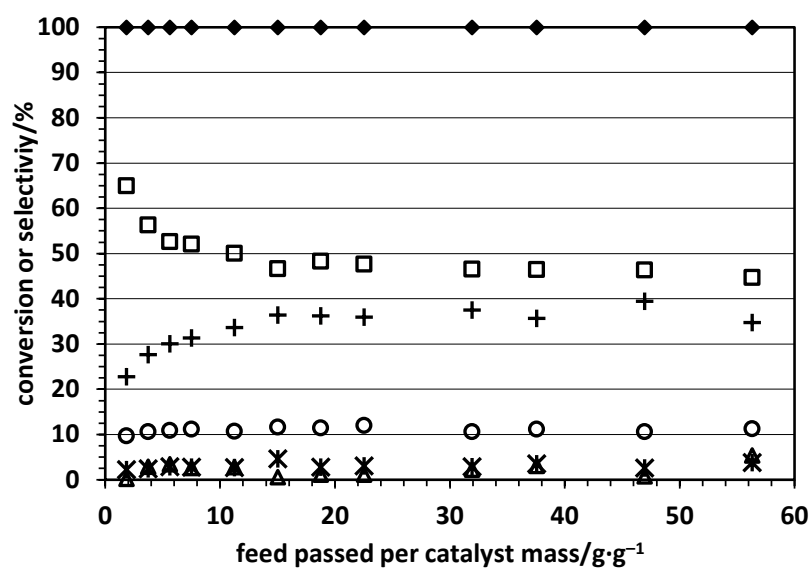


Figure 10. Development of conversion and selectivity in the organic liquid phase with time on stream when valeric acid was passed over a zirconium oxide and a Pt/C bed. conversion pentanoic acid, $\Delta$ selectivity 5-nonanone, $\square$ selectivity nonane, o selectivity to $\mathrm{C}_{10}-\mathrm{C}_{15}$ hydrocarbons, + selectivity to other hydrocarbons (up to $\mathrm{C}_{8}$ ), $*$ selectivity to oxygenated compounds.

Reaction conditions: feed rate for valeric acid: $0.15 \mathrm{~mL} / \mathrm{min}$; hydrogen gas flow: 470 $\mathrm{mL} / \mathrm{min}$; 40 bar hydrogen pressure; $400{ }^{\circ} \mathrm{C}$ reaction temperature. The yield of the water phase was 1.1 equiv. per valeric acid employed on average.

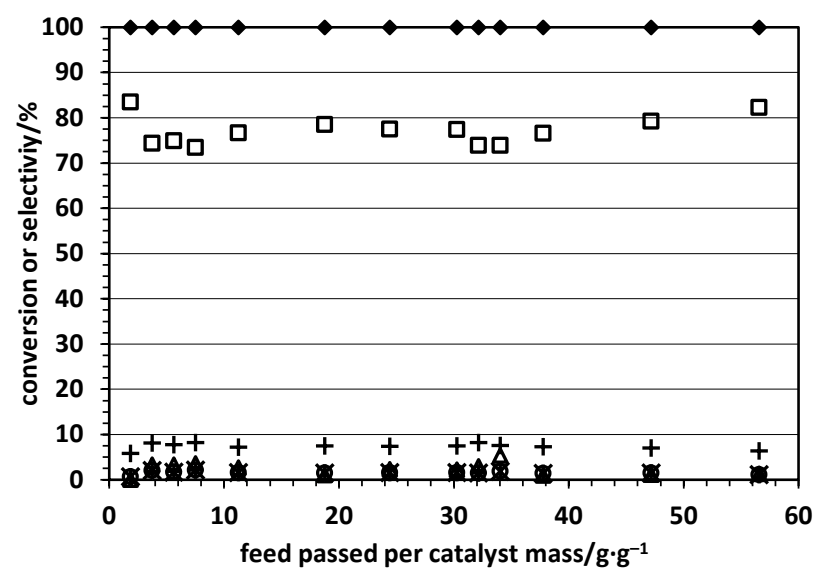


Figure 11. Development of conversion and selectivity in the organic liquid phase with time on stream when valeric acid was passed over a zirconium oxide and a Pd/alumina bed. conversion pentanoic acid, $\Delta$ selectivity 5-nonanone, $\square$ selectivity nonane, $\bigcirc$ selectivity to $\mathrm{C}_{10}-\mathrm{C}_{15}$ hydrocarbons, + selectivity to other hydrocarbons (up to $\mathrm{C}_{8}$ ), * selectivity to oxygenated compounds.

Reaction conditions: feed rate for valeric acid: $0.15 \mathrm{~mL} / \mathrm{min}$; hydrogen gas flow: 470 $\mathrm{mL} / \mathrm{min}$; 40 bar hydrogen pressure; $400{ }^{\circ} \mathrm{C}$ reaction temperature. The yield of the water phase was 1.2 equiv. per valeric acid employed on average.

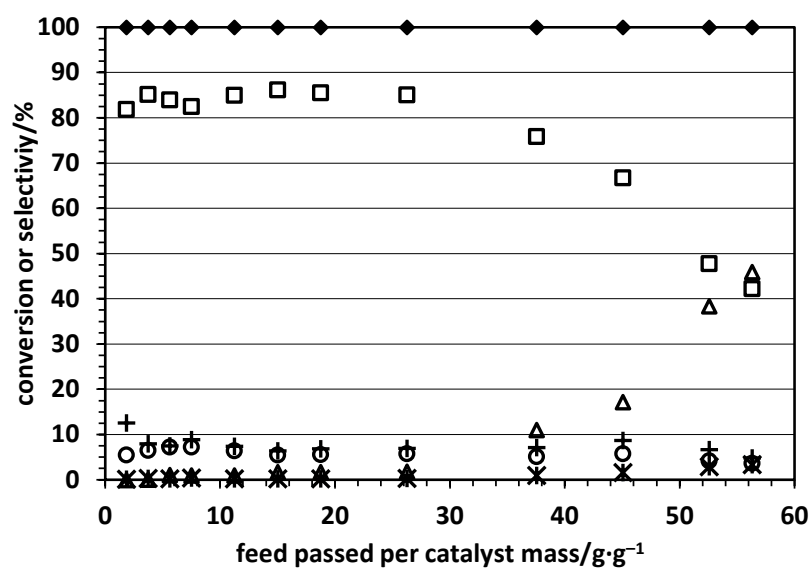

